\title{
Strain localization and damage in dual phase steels investigated by coupled in-situ deformation experiments and crystal plasticity simulations
}

\author{
Citation for published version (APA): \\ Tasan, C. C., Hoefnagels, J. P. M., Diehl, M., Yan, D., Roters, F., \& Raabe, D. (2014). Strain localization and \\ damage in dual phase steels investigated by coupled in-situ deformation experiments and crystal plasticity \\ simulations. International Journal of Plasticity, 63, 198-210. https://doi.org/10.1016/j.ijplas.2014.06.004
}

DOI:

10.1016/j.ijplas.2014.06.004

Document status and date:

Published: 01/01/2014

\section{Document Version:}

Publisher's PDF, also known as Version of Record (includes final page, issue and volume numbers)

\section{Please check the document version of this publication:}

- A submitted manuscript is the version of the article upon submission and before peer-review. There can be important differences between the submitted version and the official published version of record. People interested in the research are advised to contact the author for the final version of the publication, or visit the DOI to the publisher's website.

- The final author version and the galley proof are versions of the publication after peer review.

- The final published version features the final layout of the paper including the volume, issue and page numbers.

Link to publication

\footnotetext{
General rights

- You may freely distribute the URL identifying the publication in the public portal. follow below link for the End User Agreement:

www.tue.nl/taverne

\section{Take down policy}

If you believe that this document breaches copyright please contact us at:

openaccess@tue.nl

providing details and we will investigate your claim.
}

Copyright and moral rights for the publications made accessible in the public portal are retained by the authors and/or other copyright owners and it is a condition of accessing publications that users recognise and abide by the legal requirements associated with these rights.

- Users may download and print one copy of any publication from the public portal for the purpose of private study or research.

- You may not further distribute the material or use it for any profit-making activity or commercial gain

If the publication is distributed under the terms of Article $25 \mathrm{fa}$ of the Dutch Copyright Act, indicated by the "Taverne" license above, please 


\title{
Strain localization and damage in dual phase steels investigated by coupled in-situ deformation experiments and crystal plasticity simulations
}

\author{
C.C. Tasan ${ }^{\text {a,*, J.P.M. Hoefnagels }}{ }^{\mathrm{b}}$, M. Diehl ${ }^{\mathrm{a}}$, D. Yan ${ }^{\mathrm{a}}$, F. Roters ${ }^{\mathrm{a}}$, D. Raabe ${ }^{\mathrm{a}}$ \\ ${ }^{a}$ Max-Planck-Institut für Eisenforschung GmbH, Max-Planck-Str. 1, 40237 Düsseldorf, Germany \\ ${ }^{\mathrm{b}}$ Eindhoven University of Technology, Dep. of Mech. Eng., P.O. Box 513, 5600MB Eindhoven, The Netherlands
}

\section{A R T I C L E I N F O}

\section{Article history:}

Received 8 February 2014

Received in final revised form 28 May 2014

Available online 21 June 2014

\section{Keywords:}

A. Microcracking

A. Voids and inclusions

B. Crystal plasticity

C. Electron microscopy

Digital image correlation

\begin{abstract}
A B S T R A C T
Ferritic-martensitic dual phase (DP) steels deform spatially in a highly heterogeneous manner, i.e. with strong strain and stress partitioning at the micro-scale. Such heterogeneity in local strain evolution leads in turn to a spatially heterogeneous damage distribution, and thus, plays an important role in the process of damage inheritance and fracture. To understand and improve DP steels, it is important to identify connections between the observed strain and damage heterogeneity and the underlying microstructural parameters, e.g. ferrite grain size, martensite distribution, martensite fraction, etc. In this work we pursue this aim by conducting in-situ deformation experiments on two different DP steel grades, employing two different microscopic-digital image correlation $(\mu \mathrm{DIC})$ techniques to achieve microstructural strain maps of representative statistics and high-resolution. The resulting local strain maps are analyzed in connection to the observed damage incidents (identified by image post-processing) and to local stress maps (obtained from crystal plasticity (CP) simulations of the same microstructural area). The results reveal that plasticity is typically initiated within "hot zones" with larger ferritic grains and lower local martensite fraction. With increasing global deformation, damage incidents are most often observed in the boundary of such highly plastified zones. High-resolution $\mu$ DIC and the corresponding CP simulations reveal the importance of martensite dispersion: zones with bulky martensite are more susceptible to macroscopic localization before the full strain hardening capacity of the material is consumed. Overall, the presented joint analysis establishes an integrated computational materials engineering (ICME) approach for designing advanced DP steels.
\end{abstract}

(c) 2014 Elsevier Ltd. All rights reserved.

\section{Introduction}

Ferritic-martensitic dual phase (DP) steels are finding multiple applications in the automotive industry. There is, therefore, a permanent interest in further optimization of their microstructure aiming at lower energy consumption in sheet metal forming operations, higher energy absorption during crash loading conditions, etc. (Rashid, 1981; Llewellyn and Hillis, 1996; Calcagnotto et al., 2012; Bouaziz et al., 2013). Even when presence of other phases such as retained austenite or bainite are not taken into account, the micromechanical behavior of the composite-like dual phase microstructure of DP

\footnotetext{
* Corresponding author. Tel.: +49 2116792866.

E-mail address: c.tasan@mpie.de (C.C. Tasan).
} 
steels is rather complex (Tekoglu and Pardoen, 2010, Tekoglu et al., 2012, Kadkhodapour et al., 2011b,2011a, Sun et al., 2009a,2009b). Thus, following numerous reports on the mechanical performance of DP steel (which are typically based on conventional post-mortem microstructure characterization techniques), the microstructural strain and stress partitioning that governs the overall behavior of DP microstructures is still not fully understood.

Recently, it has been demonstrated that direct information on strain partitioning can be obtained using in-situ mechanical testing setups, which enable microstructural imaging during deformation and follow-up microscopic-digital image correlation ( $\mu$ DIC) analysis (Kang et al., 2007; Tasan et al., 2010; Ghadbeigi et al., 2010, 2013; Kapp et al., 2011; Joo et al., 2013; Marteau et al., 2013; Han et al., 2013). Kang et al. (2007) have shown that strain partitioning between ferrite and martensite can be significantly decreased by a tempering treatment, leading to an increase in the critical damage nucleation strain. Tasan et al. (2010) demonstrated that the detrimental influence of microstructural banding strongly depends on the continuity of the band, as well as its morphology and the mechanical character of the phase that composes the band. Ghadbeigi et al. (2010) have presented a quantitative analysis of critical strain levels for different damage nucleation mechanisms in a DP1000 microstructure (Ghadbeigi et al., 2010). Local strains well above $100 \%$ are reported for damage incidents within ferrite and at martensite-ferrite phase boundaries. Kapp et al. (2011), also focusing on a DP1000 steel, reported the severe heterogeneity of the strain distribution, which rises with increasing global deformation level. "Hot spots" of deformation are revealed to develop in ferrite channels between bulky martensite regions, and grain boundaries normal to the loading direction. More recently, Joo et al. (2013) have pointed out - using an advanced technique for higher strain resolution - that the strain heterogeneity in DP steels is more complex than suggested by earlier work. Marteau et al. (2013), employing a microlithography based pattern and electron backscatter diffraction (EBSD) based microstructure characterization, presented a detailed report on the role of different microstructural factors in strain heterogeneity. Their results suggest that the most critical factor causing the strain heterogeneity is the local microstructural neighborhood rather than the specific grain orientation, shape or size. These observations are also supported by a recent report by Han et al. (2013). Ghadbeigi et al. (2013) have demonstrated in a more recent work that martensite morphology is critical in early damage nucleation. Carrying out nanoindentation and micro-pillar compression experiments on martensite and ferrite regions in a DP steel, Ghassemi-Armaki et al. (2014) have shown that ferrite hardness and strength is significantly heterogeneous even within a given grain.

The results presented in the recent works clearly demonstrate the strength of the $\mu$ DIC approach in capturing the complex strain patterns evolving in DP steels. However, the nature of such in-situ analyses enforces a trade-off between representative statistics and high-resolution (e.g. lower magnification imaging allows more grains to be assessed, but with less pixels per grain), while reliable characterization of DP steel micro-mechanics requires both. The former is especially critical because the in-situ analyses at the surface of the bulk material are distracted by the behavior of the microstructure underneath, and thus may be subjected to a significant inaccuracy. Given the above-mentioned reports with the rather unexpected absence of correlation of strain localization with local microstructure properties (e.g. grain size, shape, orientation, etc.), the issue of statistical representativeness becomes even more critical. The motivation for maximal spatial resolution, on the other hand, is motivated by (i) the scale of the microstructure reaching well below the sub-micron regime within martensitic regions; and also by (ii) the locality of the plastic response in martensite and in ferrite regions.

The main goal of this report is to deepen the understanding of the role of the underlying microstructural parameters on (i) the heterogeneous plastic behavior, and (ii) the damage micro-mechanisms in DP steels. More specifically, the influences of ferrite grain size, ferrite orientation and martensite dispersion are investigated. To this end, to fulfill both the statistical and resolution requirements, we employ two different $\mu$ DIC methodologies: the first method enables the mapping of large fieldof-view microstructure patches, but at lower spatial resolution strain mapping; while the second one allows high spatial resolution strain mapping at smaller field-of-view. Both analyses are coupled to high resolution microstructure mapping based on EBSD measurements. The former is additionally coupled to the results obtained from an image post-processing based damage detection algorithm, and the latter to full-field crystal plasticity (CP) simulations. The simulations play a key role, as they provide an (indirect) analysis of the local stress partitioning process, which is otherwise challenging to access through experimentation only.

In what follows, first the employed experimental and theoretical methodologies are explained. Then, results of the aforementioned two types of in-situ deformation experiments are presented in connection to the results of the accompanying microstructure analysis and $\mathrm{CP}$ simulation results. Finally the results are discussed and conclusions are presented.

\section{Methodology}

\subsection{Materials}

The DP steels investigated in this report have a tensile strength of approximately $600 \mathrm{MPa}$ (DP600) and $800 \mathrm{MPa}$ (DP800), respectively. Both steels are non-commercial grades provided by Tata Steel, IJmuiden, the Netherlands. The microstructure of both materials consists of a soft ferrite matrix surrounded by martensite islands. Details on the composition and overall properties of these two steels are provided in Table 1. Within this study both of these steels are deformed in multiple strain paths using two different deformation setups described below. We present here the results of biaxial tension for the DP600 steel and uniaxial tension for the DP800 steel. The motivation of investigating the two microstructures in these two strain paths is as follows. As seen in Fig. 1 and Table 1, the microstructures possess differences in ferrite grain size (larger in DP600), 
Table 1

The overall characteristics of the DP600 and DP800 steels employed in this work.

\begin{tabular}{lllll}
\hline Steel & $C($ wt\% $)$ & Martensite $(\%)$ & Ferrite grain size $(\mu \mathrm{m})$ & Martensite grain size $(\mu \mathrm{m})$ \\
\hline DP600 & 0.09 & 17.2 & $8.4 \pm 6.1$ & $2.7 \pm 1.6$ \\
DP800 & 0.15 & 18.4 & $4.9 \pm 1.9$ & $1.7 \pm 1.1$ \\
\hline
\end{tabular}

martensite fraction and distribution heterogeneity (both larger in DP800). DP600 steel provides a more suitable microstructure to investigate ferrite grain size and orientation effects on damage mechanisms without a strong influence of the heterogeneity of martensite distribution. However, the DP600 microstructure is less damage-prone (due to the relatively larger ferrite grain size and lower martensite fraction) up to high strain levels where deformation-induced roughening renders the coupled analysis of large-field-of-view DIC and damage mechanisms. To avoid this practical difficulty, we choose the biaxial tension strain path which leads to a highest damage evolution rate (Hoefnagels et al., submitted for publication), and hence the stronger statistics. The DP800 microstructure, on the other hand, due to its larger martensite fraction and smaller ferrite grain size provides a better opportunity to investigate the influence of martensite distribution effects. The use of the uniaxial tension stage is preferred as it allows shorter SEM working distances, which in turn provides higher DIC resolution for the relatively finer DP800 microstructure (Table 2).

\subsection{Experimental mapping of microstructural-strain and damage}

The DP600 sample is deformed with in-situ secondary electron (SE) imaging during the straining. Prior to the deformation, its surface is prepared with conventional metallographic grinding and polishing steps to a deformation-free finish (confirmed by backscattered electron imaging), and then etched with $2 \%$ nital solution for five seconds. SE imaging of etched surfaces allows large field-of-view imaging of statistically representative areas of the microstructure, however, provides relatively low strain resolution (due to the ferritic zones without significant contrast in the etched microstructure) and limited maximum strain level (due to deformation induced roughening).

Prior to deformation, $0.05 \mu \mathrm{m}$ step size electron backscatter diffraction (EBSD) measurements are carried out on the undeformed surface microstructure that is to be tracked during deformation using a FEI Sirion scanning electron microscope (SEM). After that, the sample is deformed in biaxial tension, employing the home-built miniaturized Marciniak setup. During the Marciniak test a flat punch deforms the sample together with a washer sheet of the same geometry but with a central hole. The washer stabilizes the deformation of the sample and ensures failure in the central contact-free region deformed in biaxial tension. The details of the design and working principles of the setup are provided elsewhere (Tasan et al., 2012). This setup is placed into a FEI Quanta 600F SEM to carry out the deformation experiments. The images obtained during the
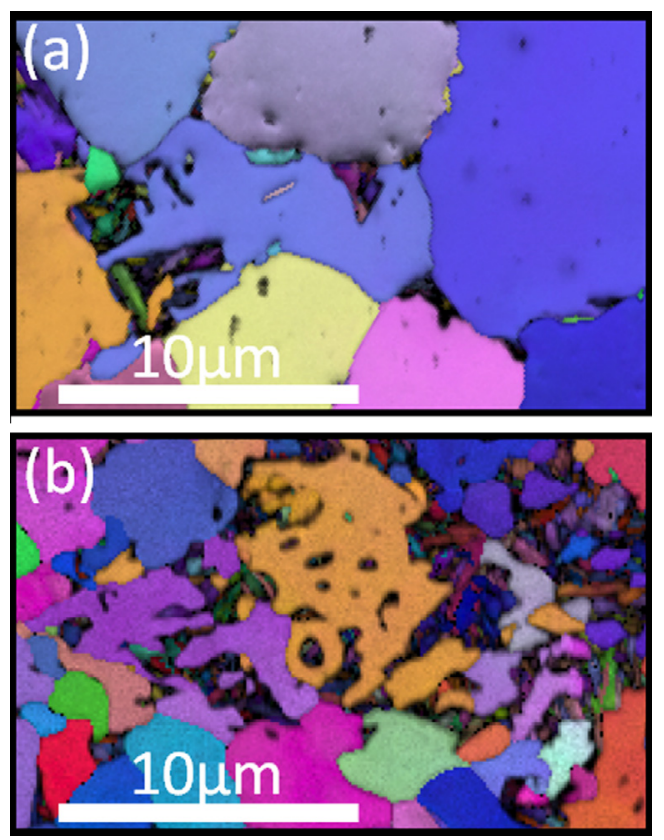

Fig. 1. The microstructures of (a) DP600 and (b) DP800 grades investigated in this report are shown in the EBSD image quality maps (grayscale) with inverse pole figure overlay. The legend for the latter is the same as in Figs. 6 and 7. Dark regions correspond to martensite. 
Table 2

Ferrite and martensite phase parameters used in the simulations. Note that the ferrite slip resistance parameters are determined through the described optimization procedure, while the martensite parameters are obtained through fitting to macroscopic stress-strain curves.

\begin{tabular}{llll}
\hline Property & Value (Ferrite) & Value (Martensite) & Unit \\
\hline$C_{11}$ & $233.3 \times 10^{9}$ & $417.4 \times 10^{9}$ & $\mathrm{~Pa}$ \\
$C_{12}$ & $235.5 \times 10^{9}$ & $242.4 \times 10^{9}$ & $\mathrm{~Pa}$ \\
$C_{44}$ & $128.0 \times 10^{9}$ & $211.1 \times 10^{9}$ & $\mathrm{~Pa}$ \\
$\dot{\gamma}_{0}$ & $1 \times 10^{-3}$ & $1 \times 10^{-3}$ & $\mathrm{~ms}^{-1}$ \\
$S_{0,[111]}$ & $95 \times 10^{6}$ & $406 \times 10^{6}$ & $\mathrm{~Pa}$ \\
$S_{\infty,[11]}$ & $22 \times 10^{6}$ & $873 \times 10^{6}$ & $\mathrm{~Pa}$ \\
$S_{0,[112]}$ & $96 \times 10^{6}$ & $457 \times 10^{6}$ & $\mathrm{~Pa}$ \\
$S_{\infty,[112]}$ & $412 \times 10^{6}$ & $971 \times 10^{6}$ & $\mathrm{~Pa}$ \\
$h_{0}$ & $1 \times 10^{9}$ & $563 \times 10^{9}$ & $\mathrm{~Pa}$ \\
$h_{\alpha \beta}$ & 1.0 & 1.0 & \\
$n$ & 20 & 20 & \\
$w$ & 2.25 & 2.25 & \\
\hline
\end{tabular}

deformation experiment are post-processed in two different manners to obtain local strain and damage incident maps. To obtain the local strain data, the Aramis software (GOM GmbH, Braunschweig, Germany) is employed to carry out digital image correlation analyses. The finer microstructure of the DP800 steel shown in Fig. $1 \mathrm{~b}$ requires high-resolution $\mu$ DIC maps, and, therefore, the sample surface is coated with finely distributed markers prior to deformation. The strength of this methodology is based on (i) achieving a homogeneous distribution of $11 \pm 4 \mathrm{~nm}$ sized $\mathrm{SiO}_{2}$ particles on the sample surface, and (ii) optimizing the inlens SE imaging conditions to get high-resolution pattern images without microstructure hindrance. To apply the particles, a colloidal silica solution is dispersed on the sample before the experiment. The imaging and $0.1 \mu \mathrm{m}$ step size EBSD measurements are carried out in a Zeiss-Crossbeam XB 1540 SEM (Oberkochen, Germany). The deformation is carried out in uniaxial tension to different deformation levels using a Kammrath \& Weiss (Dortmund, Germany) tensile stage. More details on these experiments are provided in (Tasan et al., submitted for publication).

Microstructural damage incidents lead to strong topographical changes, and the high-resolution SE images obtained insitu during deformation capture these changes as sharp gradients in the local gray value. To locate and characterize each individual damage incident, a semi-automatic image post-processing approach is employed. This approach makes use of an in-house developed Matlab algorithm that scans pixels in the SE image for sharp gray value gradients. Each determined zone is then cropped and digitally magnified in order to be confirmed by the operator as a damage incident. This methodology is also applied recently for statistical characterization of strain path and microstructure effects on the activity of different damage mechanisms (Hoefnagels et al., submitted for publication). Following the deformation experiments, the damage locations identified by image post-processing are analyzed in an integrated manner together with the EBSD maps of the undeformed microstructure and the local strain maps obtained from $\mu$ DIC to identify microstructural "hot" and "cold" zones.

\subsection{Numerical mapping of microstructural-strain and stress}

To reveal more details on the complex micromechanics of DP steels, especially regarding local stress distributions, CP simulations are carried out to accompany the experiments conducted on the DP800 microstructure. For these full-field simulations, the EBSD-based crystal orientation and average image quality data obtained on the investigated microstructural areas are taken as the starting point for the model. As in the experiments, the microstructural patches are deformed in tension under quasi-static loading conditions (i.e. with a strain rate of $10^{-3} \mathrm{~s}^{-1}$ ) to a final average strain of approximately $10 \%$. The overall integrated computational materials engineering (ICME) methodology employed is schematically shown in Fig. 2.

The employed CP formulation (Roters et al., 2010) is a modification of the phenomenological model described in (Hutchinson, 1976) for the bcc crystals incorporated in the DAMASK framework (DAMASK; Roters, 2011; Roters et al., 2012). In the chosen formulation, the microstructure is parameterized in terms of a slip resistance $s^{\alpha}(\alpha=1,2, \ldots, 24)$ on each slip system. Incorporated are $12\{110\}\langle 111\rangle$, and $12\{112\}\langle 111\rangle$ systems. These resistances increase toward the saturation stress $S_{\infty}^{\alpha}$ with shears $\gamma^{\beta}(\beta=1,2, \ldots, 24)$ according to the relationship,

$$
\dot{S}^{\alpha}=\sum_{\beta=1}^{24} \dot{\gamma}^{\beta} h_{0}\left|1-\frac{S^{\beta}}{S_{\infty}^{\alpha}}\right|^{w} \operatorname{sgn}\left(1-\frac{S^{\beta}}{S_{\infty}^{\alpha}}\right) h_{\alpha \beta}
$$

with interaction $\left(h_{\alpha \beta}\right)$ and fitting $\left(w, h_{0}\right)$ parameters. Given a set of current slip resistances, shear on each system evolves at a rate of

$$
\dot{\gamma}^{\alpha}=\dot{\gamma}_{0}\left|\frac{\tau^{\alpha}}{S^{\alpha}}\right|^{n} \operatorname{sgn}\left(\tau^{\alpha}\right)
$$



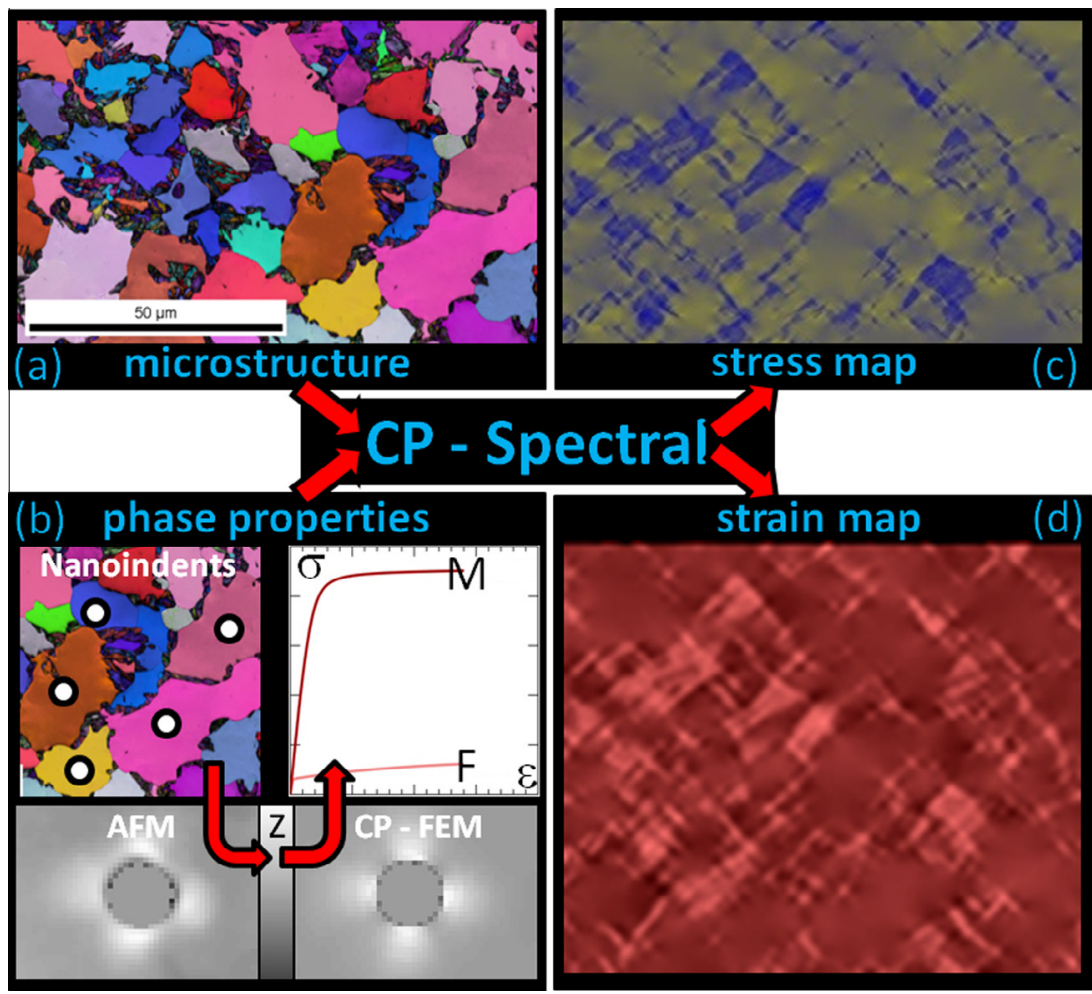

Fig. 2. Overall methodology of the joint experimental and modeling ICME approach: (a) a high resolution EBSD map is the base for the CP model, together with (b) the inverse simulation methodology that provides the ferrite phase properties. In the latter, nanoindent topographies (on grains of known crystallographic orientation) are measured with atomic force microscopy, which are taken (together with the load displacement curves) as the optimization criteria for the CPFEM simulations. With these ingredients the crystal plasticity simulations are run employing a dedicated spectral solver to provide stress and strain maps of the analyzed microstructure.

where $\tau^{\alpha} \boldsymbol{S} \cdot\left(\boldsymbol{b}^{\alpha} \otimes \boldsymbol{n}^{\alpha}\right)$ with $\boldsymbol{S}$ being the external stress tensor and $\boldsymbol{b}^{\alpha}$ and $\boldsymbol{n}^{\alpha}$ being the unit vectors along the slip direction and slip plane normal, respectively; and $\dot{\gamma}_{0}$ is the reference shear rate and $n$ is the stress exponent. The superposition of shear on all slip systems determines the plastic velocity gradient $\boldsymbol{L}_{p}$,

$$
\boldsymbol{L}_{p}=\sum_{\alpha=1}^{24} \dot{\gamma}^{\alpha}\left(\boldsymbol{b}^{\alpha} \otimes n^{\alpha}\right)
$$

The parameters used to model the ferrite and martensite constitutive response are given in Table 2 . Within this study, ferrite phase properties are identified by an optimization procedure based on nanoindentation experiments carried out on the DP800 steel being investigated. This methodology is described in detail in (Zambaldi et al., 2012) and its application (to titanium) is presented in (Yang et al., 2011), thus only the general aspects are repeated here. First, load controlled nanoindentation experiments are carried out on various ferrite grains with different, EBSD-determined, crystallographic orientations. Then, load-displacement data and the surface pile-up topography around selected indents, the latter measured with followup atomic force microscopy (AFM) measurements, are taken as the touchstone to which the CP parameters are optimized by doing simulations of the nanoindentation experiments. While exactly the same CP model introduced earlier is used for the simulations, the complex shape of the indentation experiment requires to use the finite element method (FEM) instead of spectral method. Earlier work reveals that both formulations provide similar micro-mechanical response (Eisenlohr et al., 2013). More details on the application of this optimization procedure for the determination of ferrite parameters are given in (Tasan et al., submitted for publication).

This procedure can only be applied to the ferrite phase, as the dimensions of the martensitic lathes are of similar size as the nanoindents. Therefore, for the martensite, constitutive parameters are fitted to macroscopic stress-strain curves of single-phase martensite polycrystals (Tjahjanto et al., 2008). However, to strengthen the correlation with the microstructure at hand, initial and final shear stress on each slip system family in the martensite under investigation is scaled to produce the same initial flow stress ratio measured from the nanoindentation experiments on ferrite and martensite. Note that the inaccuracy due to this approximation is investigated in a concurrent study, which reveals that martensite properties have a relatively weak influence (with respect to, e.g., martensite morphology and distribution) on the level of strain partitioning between the two phases (Tasan et al., submitted for publication). 
The complexity of the DP microstructures shown in Fig. 1 requires an efficient pre-processing and solution procedure. To this end, a recently developed spectral solver is used in this study (Shanthraj et al., 2014). The use of the spectral solver creates four main benefits: (i) high fidelity of the numerical solution due to the underlying spectral ansatz functions, (ii) faster computation, (iii) ability to capture large gradients in phase properties, and (iv) the simple point wise input of the EBSD data without the necessity of meshing. Note that for the latter phase classification (as ferrite or martensite) is carried out based on EBSD grain average image quality values (Tasan et al., submitted for publication). On the other hand, since the spectral method uses trigonometric polynomials for the approximation of boundary value problem, the microstructure is periodically repeated in all three directions, i.e. periodic boundary conditions are enforced (Eisenlohr et al., 2013). The effects of this artificial periodicity are analyzed by two sets of preceding simulations.

The effect of in-plane periodicity is studied by simulating different subsets of the chosen ROI, which revealed that the direct surrounding is most decisive for the stress and strain partitioning. Taking also into account that the local boundary conditions on the edges of the selected ROI are unknown anyway, the in-plane periodic repetition is a valid assumption. Nevertheless, to reduce such in-plane effects further the simulated microstructural areas are kept larger than those tracked experimentally.

The effect of the out-of-plane repetition (i.e. infinite columnar grain assumption) is studied by introducing a layer of a material with low stiffness (isotropic linear-elastic with $\mathrm{c}_{11}=417.4 \mathrm{~Pa}, \mathrm{c}_{12}=242.4 \mathrm{~Pa}$ ) in the third direction. To avoid extremely high grid distortion at the interface, the DP microstructure is extruded to 8 Fourier points (FP) and the soft layer is resolved by 6 FPs. Nevertheless, a decrease in convergence (due to the increased stiffness contrast) and a dramatic increase in computational time (due the 16 times higher number of material points compared to the original simulation) are observed. No significant differences are determined in terms of the stress and strain partitioning behavior compared to the selected generalized plane-stress load case where the average stress in the third direction is set to zero by adjusting the prescribed deformation gradient.

\section{Results}

\subsection{Influence of ferrite properties}

As a first step into the analysis of strain and damage heterogeneity in DP steels, the results of the experiments on the DP600 steel sample are presented (Fig. 3). In-situ biaxial tension deformation experiments carried out with the miniaturized Marciniak setup provide SE images (Fig. 3a) and the corresponding $\mu$ DIC maps (Fig. 3b). The evolution of the strain heterogeneity at a magnified region (indicated by a black rectangle in Fig. $2 b_{4}$ ) is presented in Fig. $3 c$.

Despite the surface roughening observed in the SE images in Fig. 3a, the $\mu$ DIC methodology successfully captures almost a full strain map based on the tracking of the etched surface features. Note, however, that the local strains at the martensite islands are averaged together with the surrounding ferritic grains, due to the small dimensions of the martensite in the DP600 grade steel (Fig. 1a). The analyses provided in Fig. 3b and c reveal that a strong heterogeneity develops in the strain distribution (ranging from local strain values of 0.05-0.20). This is in accordance with the aforementioned studies. Intensely strained zones in the microstructure (marked in Fig. $3 c_{4}$ with numbers 1-10) enter into the plastic deformation regime first, followed by the formation of high strain channels between these zones.

Next, the EBSD measurements carried out at the undeformed state (Fig. 4) are analyzed to investigate whether any microstructural features correspond to the preferentially deforming zones observed in Fig. 3b and c. In Fig. 4a, an EBSD-based grain size map and in Fig. 4b an EBSD-based Taylor factor map of the area shown in Fig. $3 \mathrm{c}$ are provided. It is observed that the highly deformed grains marked $1-10$ in Fig. $3 c_{3}$, are all larger than $15 \mu \mathrm{m}$ in diameter, i.e. above the average ferrite grain size. Fig. $3 \mathrm{~b}$ reveals that there is no distinct correlation between Taylor factor and the highly deformed grains. Thus, the effect of grain size is more dominant than the effect of crystallographic orientation for the initiation of plasticity. This observation is consistent in other regions in Fig. 3b as well, apart from those regions where significant local heterogeneities in martensite distribution and fraction govern the strain heterogeneity.

Careful assessment of the SE images taken during the in-situ deformation experiment allows tracking of damage nucleation and growth in the area presented in Fig. 3b. A zoom-in example of such a damage incident is shown in Fig. 5a. Each such incident is registered by image gray-value post-processing and marked by a black square in Fig. $5 \mathrm{~b}$ to provide the distribution of damage incidents at the end of the deformation experiment.

As it is the case for the plastic strain presented in Fig. 3, the damage incidents are also heterogeneously distributed, such that damage-free zones (as large as $35 \mu \mathrm{m}$ radius) are observed together with damage-prone zones (with as much as 7 damage incidents within $10 \mu \mathrm{m}$ radius). Plotting the two maps on top of each other (Fig. 5c) reveals that most damage sites are located at the borders between high deformation zones (which are determined in the analyses provided in Fig. 4 to be larger ferrite grains) and the surrounding low deformation zones (i.e. smaller ferrite grains or martensitic regions).

\subsection{Influence of martensite dispersion}

Due to the low content of martensite in the DP600 microstructure, it is challenging to investigate the role of the martensite dispersion on the strain heterogeneity on this material. As shown in Fig. 1, the DP800 steel microstructure is more suited 

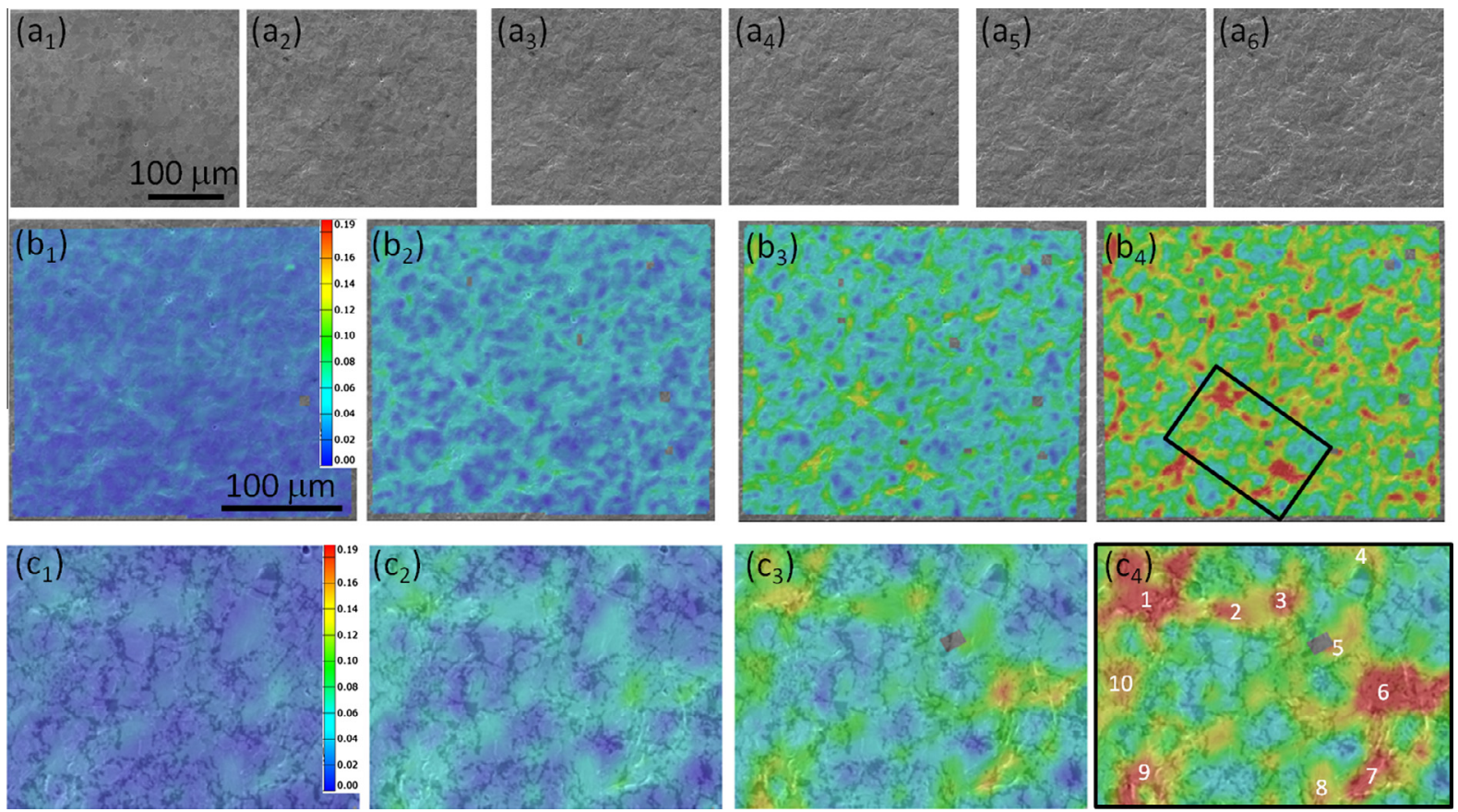

Fig. 3. Results obtained during the in-situ biaxial tension deformation experiment: (a) SE images, (b) local strain maps obtained by post-processing the SE images, (c) zoom-in region from these maps (location indicated by black rectangle in $\left(b_{4}\right)$ ). Note the numerical markers on the grains in ( $\left.c_{4}\right)$. In all rows, strain increases from left to right.

for such an investigation. Therefore, high-resolution strain mapping experiments are carried out on two different positions of the DP800 sample (results are presented in Figs. 6 and 7). The two regions differ mainly in the distribution of martensite, and also slightly in the area fraction of martensite (see Fig. $6 b_{1}$ for microstructure "a" and Fig. $7 b_{1}$ for microstructure "b"). In these figures, the deformation-induced evolution of surface topography, strain distribution, local average misorientation distribution and orientation are provided respectively in rows a-d. The corresponding CP simulations are presented in Fig. 8.

The SE images provided in Fig. 6a for microstructure "a", reveals significant surface roughening already at a von Mises strain of 0.061 , developing a topography of "hills and valleys" up to $1 \mu \mathrm{m}$ in height (Fig. $6 \mathbf{a}_{2}$ ). Apart from the expected roughening influence of slip traces and grain rotations, damage incidents, which correspond to suddenly appearing dark spots in Fig. $6 a_{2}$ and $a_{3}$, also contribute to the roughening observed here. Upon closer inspection, it is seen that regions with high martensite connectivity are especially susceptible to micro-cracking.

In comparison, the microstructure "b" with lower martensite content, but bulkier martensite islands shown in Fig. 7, has zones with almost no roughness development (see bottom left or top middle zones in Fig. $7 \mathrm{a}_{3}$ in comparison to the microstructure in Fig. $6 a_{3}$ ). Focusing on the final strain maps provided in Figs. $6 b_{3}$ and $7 b_{3}$, and the final local average misorientation maps in Figs. $6 c_{3}$ and $7 c_{3}$, two observation can be made: First, the higher resolution strain mapping technique employed here reveals for both microstructural regions that the plastic strain is accommodated in a much more heterogeneous manner than it was suggested by the earlier maps provided in Fig. 3. This observation can also be verified by the locality of the deformation-induced orientation changes tracked in the inverse pole figures presented in Figs. $6 \mathrm{~d}$ and $7 \mathrm{~d}$. Second, when the martensite is more homogeneously distributed such that each ferrite grain neighbors a martensite island (as in microstructure "a", Fig. 6), a greater portion of the ferritic grains contribute to accommodating plasticity. The opposite case is observed when the martensitic regions are more blocky and heterogeneously distributed (such that only few ferrite grains neighbor a martensite island), leading to plastic strain accommodation mainly by certain ferritic grains (see the ferritic zone laying diagonal from upper left to lower right corner in Fig. 7) while others stay almost undeformed. Note also that for the example in Fig. 7, this occurs despite the relatively large size of the ferritic grains neighboring the two bulky martensite regions. To investigate this latter observation further and to analyze the stress partitioning in the two microstructures considered in Figs. 6 and 7, the CP simulation results presented in Fig. 8 will be discussed next.

For microstructure "a" (experimental results in Fig. 6), the evolution of the local von Mises strain and stress patterns obtained by the CP simulations are given in Fig. $8 \mathrm{a}$ and b, respectively. Fig. $8 \mathrm{c}$ and d provide the corresponding data for microstructure "b" (experimental results in Fig. 7). Starting with an overall comparison of the strain fields obtained from experiments and simulations (Fig. $6 b_{3}$ vs. Fig. $8 a_{3}$, and Fig. $7 b_{3}$ vs. Fig. $8 c_{3}$ ) in can be seen that the simulations successfully predict the general strain pattern observed in both microstructures. For example, for both microstructures the majority of 

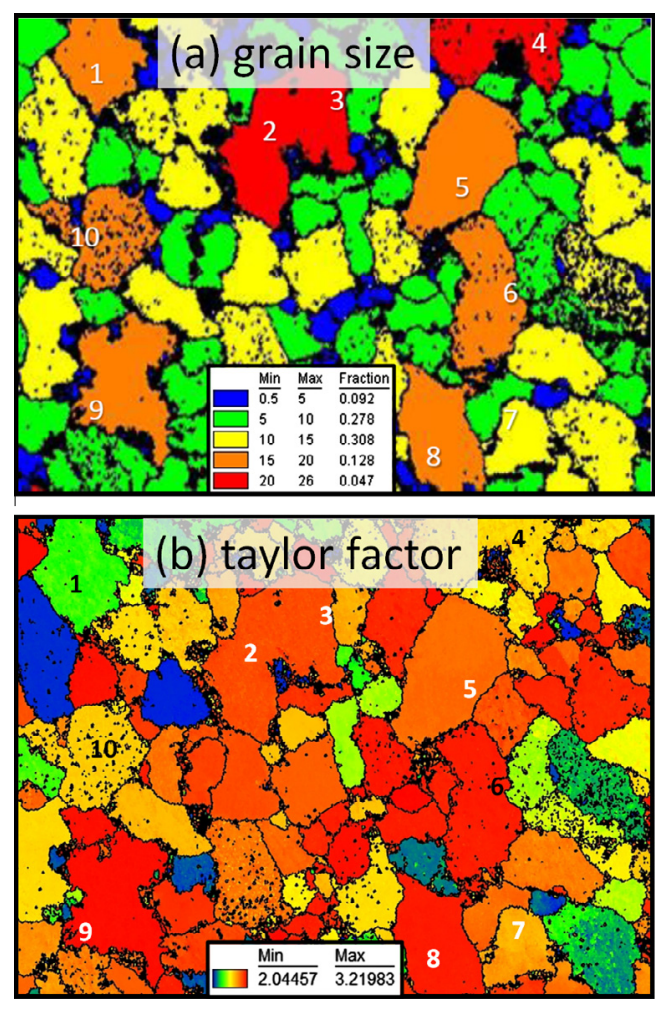

Fig. 4. EBSD-based maps obtained before deformation at the region investigated in Fig. 3c: (a) Grain size map. (b) Taylor factor map. Note also the numerical markers of the grains in Fig. $3 \mathrm{c}_{4}$.
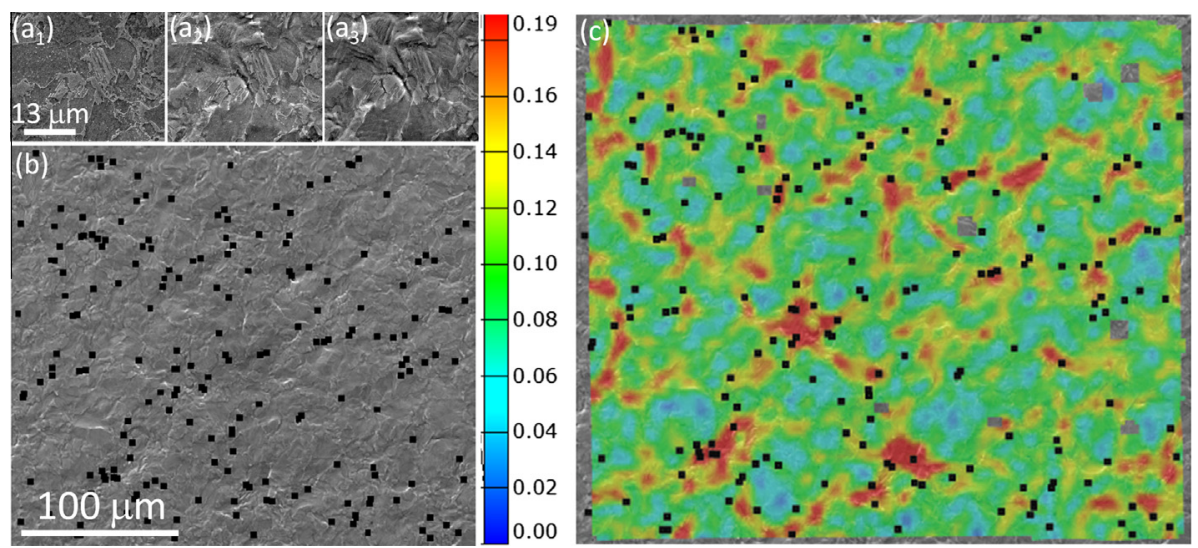

Fig. 5. Damage events captured during the in-situ experiments presented in Fig. 3. (a) High magnification crop showing micro-cracks near a martensiteferrite phase boundary. (b) Each damage event in the low-magnification image is represented with black dots. (c) Damage incidents are overlaid with the local strain map.

the plastic strain is accommodated in the diagonal ferritic band (that extends from the upper left to the lower right corner in both cases) in simulation and experiment. On the other hand, upon careful examination, it is observed that the simulations do not capture some of the sharp strain localization bands measured experimentally. Examples for such incidents are the high (red) strain bands in Figs. $6 b_{3}$ and $7 b_{3}$. These are believed to correspond to sub-surface damage incidents. Finally, comparing the numerically obtained strain maps in Fig. $8 a_{3}$ and $c_{3}$ with each other it can also be noticed that there is higher strain variation in the ferritic regions of microstructure "a" compared to the ferritic regions of microstructure "b".

Examining the stress maps of the two microstructures (Fig. 8b vs. Fig. 8d) reveals three main observations: First, as expected, the martensite phase is carrying majority of the applied stress (compared to ferrite) in both microstructures. Second, the stress is locally highest at those martensitic regions that are narrowest and that lay parallel to the loading 


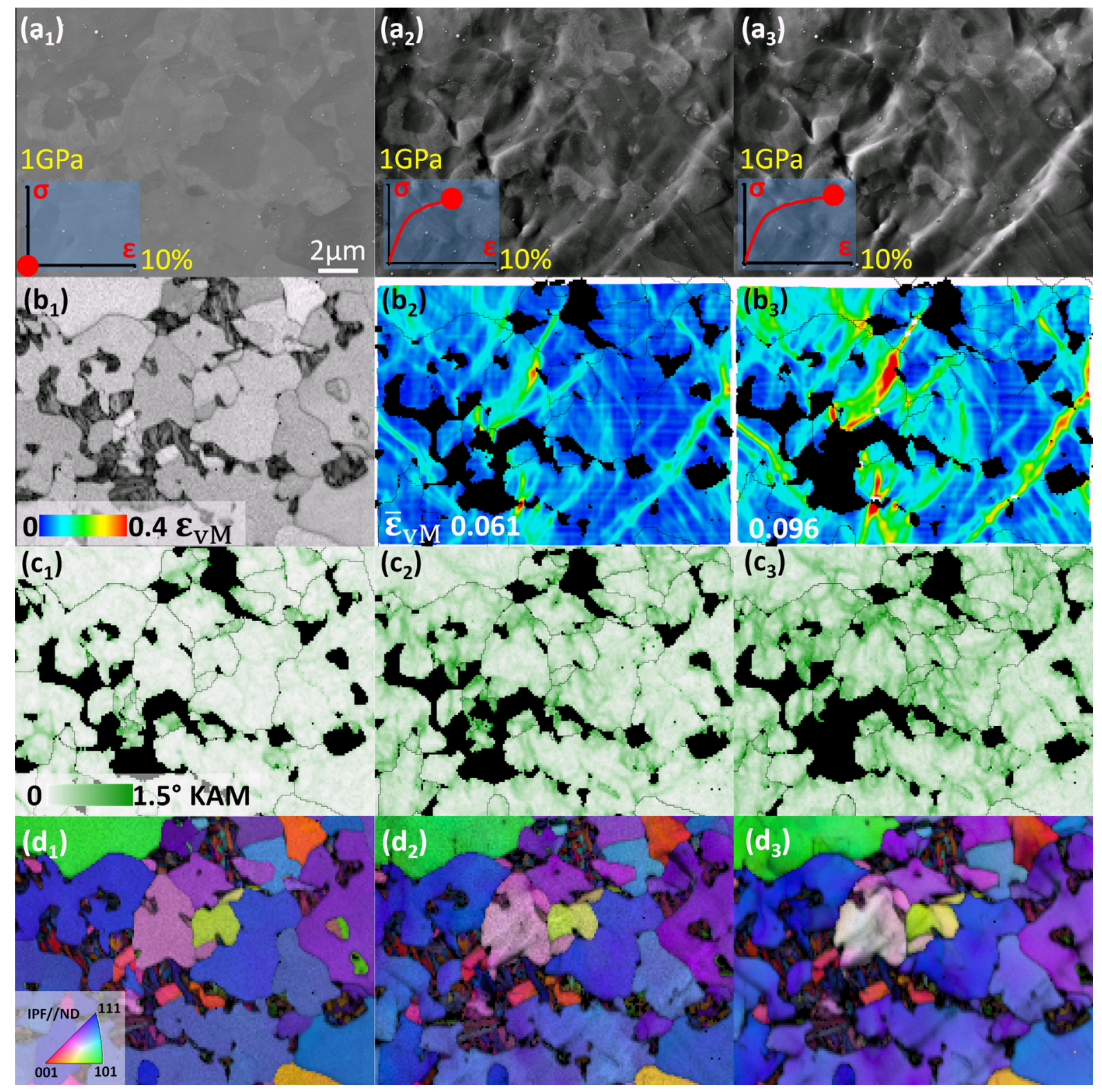

Fig. 6. Results of the uniaxial tension deformation experiments of the DP800 alloy for the region with the well-dispersed martensite distribution (microstructure "a") at different levels of deformation in horizontal loading direction (see row (b)): (a) secondary electron images with an inset of the global stress-strain response. $\left(b_{1}\right)$ EBSD-based image quality map of the undeformed microstructure, $\left(b_{2}-b_{3}\right)$ local von Mises strain maps (martensite regions shown in black). (c) Kernel average misorientation (martensite regions shown black). (d) Inverse pole figure maps.

direction. And finally, third, for the microstructure with a more homogeneous martensite distribution (microstructure "a"), the average stress carried by the martensite is lower. This latter point is quantitatively demonstrated in Fig. 9 where the overall stress-strain response data of the two microstructural regions is presented in Fig. 9a and the strain partitioning between ferrite and martensite in these two regions is presented in Fig. $9 \mathrm{~b}$.

Herein Fig. 9 two aspects are worth noting. First, as observed in Fig. 9a, the stress-strain response of these two microstructural regions are almost identical. The microstructure analyzed in Fig. 7, denoted as "a" has a slightly stronger response compared to the microstructure analyzed in Fig. 6, denoted as "b". This is surprising, since the overall martensite content in the former region is slightly higher (see Fig. $7 b_{1}$ vs. Fig. $6 b_{1}$ ). Second, as observed in Fig. $9 b$, there is on average a more pronounced strain partitioning in microstructure "a" compared to microstructure "b". This suggests that the stress partitioning between the two phases must be more significant (i.e. martensite carries a larger portion of the applied stress) in 


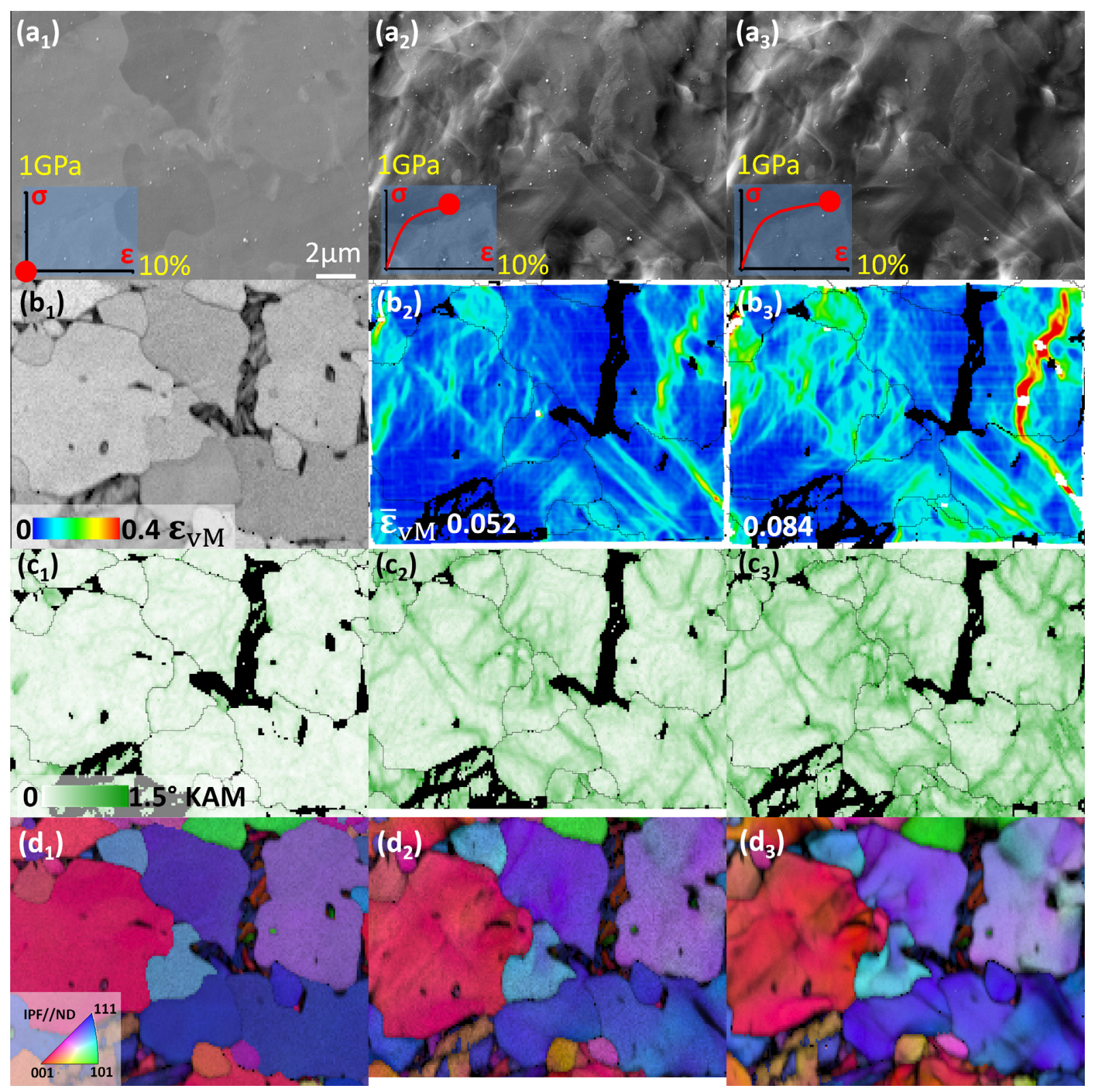

Fig. 7. Results of the uniaxial tension deformation experiments of the DP800 alloy for the region with lower martensite volume fraction and larger martensite islands (microstructure "b") at different levels of deformation in horizontal loading direction (see row (b)): (a) secondary electron images with an inset of the global stress-strain response. $\left(b_{1}\right)$ EBSD based image quality map of the undeformed microstructure, $\left(b_{2}-b_{3}\right)$ local von Mises strain maps (martensite regions shown in black). (c) Kernel average misorientation (martensite regions shown black). (d) Inverse pole figure maps.

microstructure "a" compared to microstructure "b", which is in accordance with the qualitative analysis made above based on the stress maps provided in Fig. 8b and d.

\section{Discussion}

The detailed results provided above, based on complementary experimental and numerical methodologies applied to two different DP steel grades, provide a number of micromechanical points to be discussed in a comparative manner.

For DP microstructures with large ferrite grains and relatively small martensite islands (i.e. of low martensite volume fraction), such as the DP600 steel microstructure considered here, it is demonstrated that the ferrite grain size plays the most important role for strain heterogeneity. Localized plasticity that is initiated in large ferritic grains spreads in the form of narrow strain bands throughout the microstructure (Fig. 3b). We observe early damage nucleation in these microstructures, 

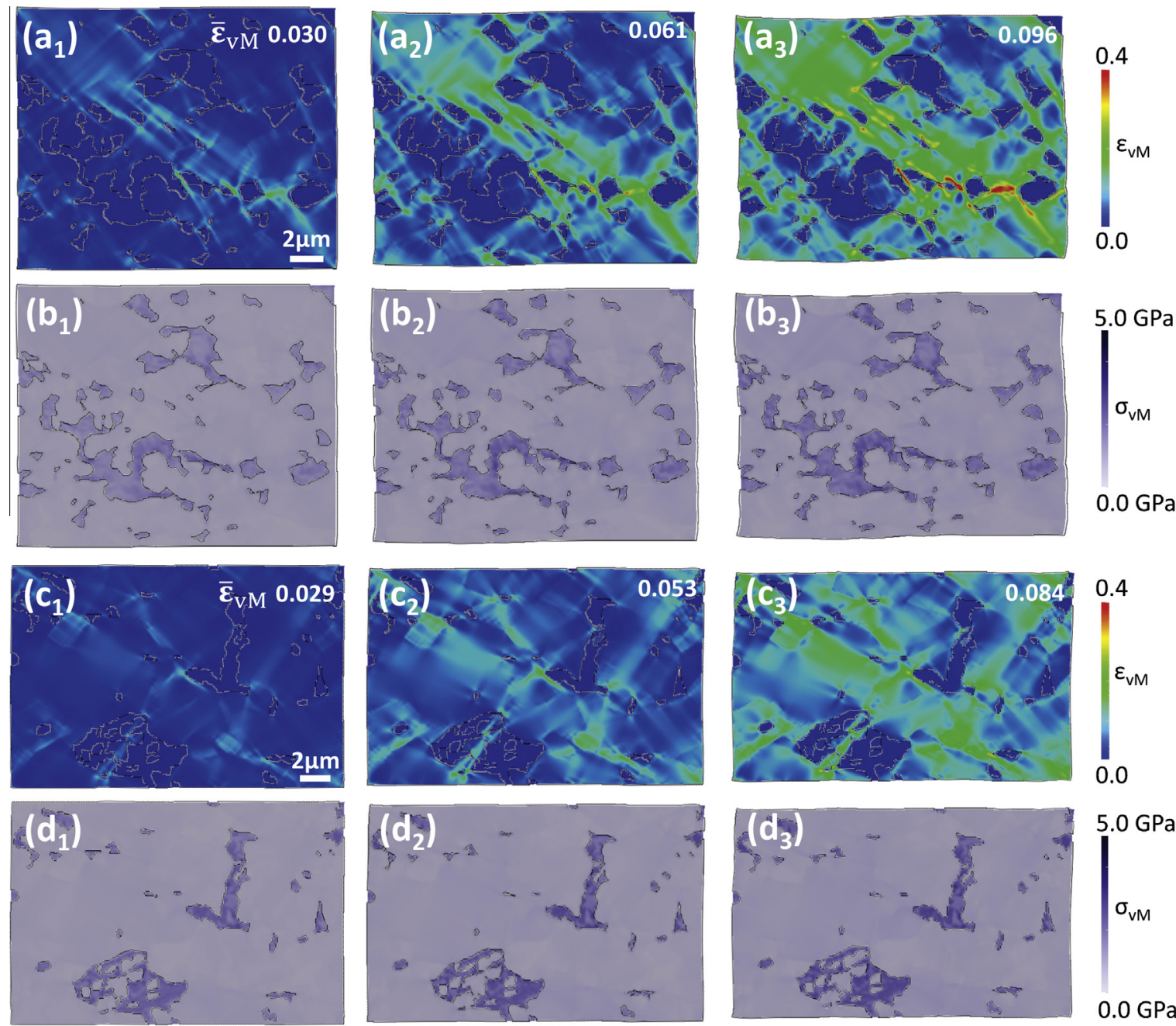

Fig. 8. Results obtained from the $\mathrm{CP}$ spectral simulations of the two microstructural regions (studied experimentally in Figs. 6 and 7 ) are presented for different average strain levels in horizontal loading direction (shown in the upper right corner of (a)): (a, c) von Mises strain and (b, d) von Mises stress maps.

suggesting strain incompatibility. More interestingly, nearly undeformed regions prevail in between these highly strained zones and narrow strain bands, even at high average strain levels. As these regions possess significant portions of ferritic grains (see, e.g., Fig. $3 c_{4}$ ), it thus appears that the full strain hardening capacity of the microstructure is not exploited during the deformation.

When the grain size is decreased and the martensite content is increased strain partitioning behavior shows considerable changes. In general, larger ferritic regions still accommodate significant amounts of strain. However, depending on the distribution and fraction of martensite, the heterogeneity of plastic strain accommodation differs. When martensite is fine and rather homogeneously distributed throughout the ferritic matrix, many fine strain bands are created, allowing more of the ferritic areas to contribute in accommodating plastic deformation. In comparison, when the martensite fraction is lower, but existing martensite islands are large and blocky, these martensite regions accommodate more stress, and the strain is more dominantly accommodated in only certain ferritic grains that lay in locations of highest shear. Thus, it can be expected that the latter type of microstructures experience macroscopic localization (and therefore failure) already at much lower macroscopic loads than the microstructures with finer dispersion of martensite. Recent reports on good strength and ductility in ultra-fine grained DP steels support these observations (Calcagnotto et al., 2012).

When comparing our current observations on damage mechanisms in these materials, it is clear that more damage incidents are identified for those microstructures that are characterized by a homogeneous martensite topology and dispersion (see Fig. $6 a_{3}$ vs. Fig. $7 a_{3}$ ). Upon first consideration, this might appear to contradict the above conclusion, namely, that microstructure refinement actually delays (rather than promotes) macroscopic localization. However, the contradiction exists only when anticipating that an observation of an increased density of micro-damage events at low strain levels implies directly also earlier macroscopic localization and fracture at relatively low macroscopic strain levels. Whether this connection is true 

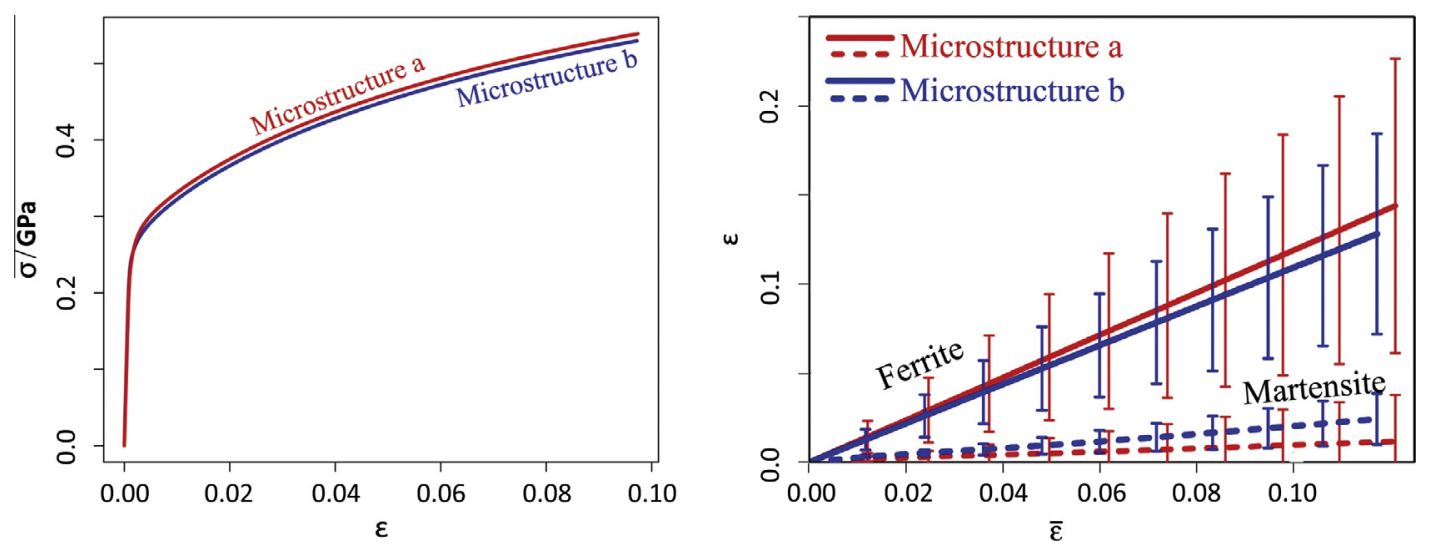

Fig. 9. Quantitative results from the CP simulations on the two microstructures studied: (a) averaged stress-strain curves. (b) Stress and strain partitioning between martensite and ferrite.

or not, however, depends strongly on the ferritic regions surrounding these early-stage damage incidents. Given that the ferrite grains can successfully arrest the nucleated damage incidents (through localized hardening), early-stage damage nucleation may actually assist in dispersing the local increase of stress and hence stabilize the macroscopic deformation.

Thus, these considerations on the relationship between "optimal" DP microstructures and damage behavior underline the importance of designing and processing DP steels with a high degree of microstructural homogeneity and phase dispersion. The finer the microstructure is, and the more optimal the ferrite topology accommodates local damage initiation, the higher is the material's efficiency in exploiting its full strain hardening capacity. Even damage nucleation, a mechanism often related to softening, may be beneficial for this purpose when it assists to disperse the deformation evenly throughout the microstructure. The results also reveal that an optimal design of DP steels and related high-mechanical contrast heteromaterials can be profoundly improved through a better understanding of the interplay between local microstructures, stresses, and strains enabled by an ICME approach. Here, specifically the capability of combining experimental mappings taken at a high field of view with corresponding full-field mechanical simulations of complex microstructures exposed to various loading conditions becomes a crucial tool.

\section{Conclusions}

Plastic deformation in dual phase (DP) steels develops as a network of deformation nodes, bands and encapsulated regions. Depending on the specific characteristics of a given dual phase microstructure (i.e. regarding ferrite and martensite fractions, dispersion and grain size), this strain localization process is strongly affected. The analyses carried out here reveal that the larger ferrite grains typically plastify earlier than smaller ones, and thus act as the initial deformation nodes in the developing microstructural strain network. The deformation proceeds then by the formation of high deformation bands connecting these nodes. Damage incidents are finally observed at the boundaries of these highly deformed zones and the surrounding microstructure. This process is most obvious for coarser DP microstructure with more homogeneously distributed, smaller martensite islands. Experiments employing high resolution microstructural strain mapping reveal that the developed microstructural strain network is significantly changed when the martensite distribution is more heterogeneous, especially when the ferrite grain size is also finer with respect to the martensite island size. While in microstructure regions with well-dispersed martensite islands majority of the ferritic regions is observed to contribute to strain accommodation and hardening, for other microstructures with bulky martensites wider localization bands are developed, the position and propagation of which is primarily governed by the position of the bulky martensite islands, possibly leading also to earlier macroscopic strain localization. Therefore, from a microstructure design point of view, the results presented here favor grain refinement and martensite dispersion for optimal DP steel mechanical behavior.

\section{Acknowledgements}

We are grateful to Rick Peters for his contributions in the experiments with the DP600 steel and Claudio Zambaldi for his aid with the indentation analysis and the inverse simulations. This research was partly carried out under project number M41.2.10410 in the framework of the research program of the Materials innovation institute M2i (www.m2i.nl) and was partly financially supported by an ERC advanced grant "SMARTMET".

\section{References}

Bouaziz, O., Zurob, H., Huang, M., 2013. Driving force and logic of development of advanced high strength steels for automotive applications. Steel Res. Int. 84, 937-947. 
Calcagnotto, M., Ponge, D., Raabe, D., 2012. Microstructure control during fabrication of ultrafine grained dual-phase steel: characterization and effect of intercritical annealing parameters. ISIJ Int. 52, 37-41.

DAMASK, 2014. Düsseldorf Advanced Material Simulation Kit. <http://damask.mpie.de/>.

Eisenlohr, P., Diehl, M., Lebensohn, R., Roters, F., 2013. A spectral method solution to crystal elasto-viscoplasticity at finite strains. Int. J. Plast. 46, 37-53. Ghadbeigi, H., Pinna, C., Celotto, S., Yates, J.R., 2010. Local plastic strain evolution in a high strength dual-phase steel. Mater. Sci. Eng., A 527, 5026-5032.

Ghadbeigi, H., Pinna, C., Celotto, S., 2013. Failure mechanisms in DP600 steel: initiation, evolution and fracture. Mater. Sci. Eng., A 588, $420-431$.

Ghassemi-Armaki, H., Maaß, R., Bhat, S.P., Sriram, S., Greer, J.R., Kumar, K.S., 2014. Deformation response of ferrite and martensite in a dual-phase steel. Acta Mater. 62, 197-211.

Han, Q., Kang, Y., Hodgson, P.D., Stanford, N., 2013. Quantitative measurement of strain partitioning and slip systems in a dual-phase steel. Scripta Mater. 69, $13-16$.

Hoefnagels, J.P.M., Tasan, C.C., Peters, F.J., Maresca, F., Kouznetsova, V.G., 2014. Retardation of plastic instability via damage-enabled micro-strain delocalization. (submitted for publication).

Hutchinson, J.W., 1976. Bounds and self-consistent estimates for creep of polycrystalline materials. Proc. Roy. Soc. A 348, $101-127$.

Joo, S.-H., Lee, J.L., Koo, J.-M., Lee, S., Suhd, D.-W., Kim, H.S., 2013. Method for measuring nanoscale local strain in a dual phase steel using digital image correlation with nanodot patterns. Scripta Mater. 68, 245-248.

Kadkhodapour, J., Schmauder, S., Raabe, D., Ziaei-Rad, S., Weber, U., Calcagnotto, M., 2011a. Experimental and numerical study on geometrically necessary dislocations and non-homogeneous mechanical properties of the ferrite phase in dual phase steels. Acta Mater. 59, 4387-4394.

Kadkhodapour, J., Butz, A., Ziaei-Rad, S., Schmauder, S., 2011b. A micro mechanical study on failure initiation of dual phase steels under tension using single crystal plasticity model. Int. J. Plast. 27, 1103-1125.

Kang, J., Ososkov, Y., Embury, J.D., Wilkinson, D.S., 2007. Digital image correlation studies for microscopic strain distribution and damage in dual phase steels. Scripta Mater. 56, 999-1002.

Kapp, M., Hebesberger, C., Kolednika, O., 2011. A micro-level strain analysis of a high-strength dual-phase steel. Int. J. Mater. Res. 102, 674-686.

Llewellyn, D.T., Hillis, D.J., 1996. Dual phase steels. Ironmak. Steelmak. 23, 471-478.

Marteau, J., Haddadi, H., Bouvier, S., 2013. Investigation of strain heterogeneities between grains in ferritic and ferritic-martensitic steels. Exp. Mech. 53, 427-439.

Rashid, M.S., 1981. Dual phase steels. Annu. Rev. Mater. Sci. 11, 245-266.

Roters, F., 2011. Advanced Material Models for the Crystal Plasticity Finite Element Method - Development of a General CPFEM Framework. RWTH Aachen, Aachen, 2011. <http://darwin.bth.rwth-aachen.de/opus3/volltexte/2011/3874/>.

Roters, F., Eisenlohr, P., Hantcherli, L., Tjahjanto, D., Bieler, T., Raabe, D., 2010. Overview of constitutive laws, kinematics, homogenization, and multiscale methods in crystal plasticity finite element modeling: theory, experiments, applications. Acta Mater. 58, $1152-1211$.

Roters, F., Eisenlohr, P., Kords, C., Tjahjanto, D., Diehl, M., Raabe, D., 2012. DAMASK: the Düsseldorf advanced material simulation kit for studying crystal plasticity using an FE based or a spectral numerical solver. In: Cazacu, O. (Ed.), Procedia IUTAM: IUTAM Symposium on Linking Scales in Computation: From Microstructure to Macroscale Properties, vol. 3. Elsevier, Amsterdam, pp. 3-10.

Shanthraj, P., Eisenlohr, P., Diehl, M., Roters, F., 2014. Numerically robust spectral methods for crystal plasticity simulations of heterogeneous materials. Int. J. Plast. (in press).

Sun, X., Choi, K.S., Soulami, A., Liu, W.N., Khaleel, M.A., 2009a. On key factors influencing ductile fractures of dual phase (DP) steels. Mater. Sci. Eng. A-Struct. Mater. Prop. Microstruct. Process. 526, 140-149.

Sun, X., Choi, K.S., Liu, W.N., Khaleel, M.A., 2009b. Predicting failure modes and ductility of dual phase steels using plastic strain localization. Int. J. Plast. 25, 1888-1909.

Tasan, C.C., Hoefnagels, J.P.M., Geers, M.G.D., 2010. Microstructural banding effects clarified through micrographic digital image correlation. Scripta Mater. $62,835-838$.

Tasan, C.C., Hoefnagels, J.P.M., Dekkers, E.C.A., Geers, M.G.D., 2012. Multi-axial deformation setup for microscopic testing of sheet metal to fracture. Exp. Mech. 52, 669-678.

Tasan, C.C., Diehl, M., Yan, D., Zambaldi, C., Shanthraj, P., Roters, F., Raabe, D., 2014. Integrated experimental-numerical analysis of stress and strain partitioning in multi-phase alloys. (submitted for publication).

Tekoglu, C., Pardoen, T., 2010. A micromechanics based damage model for composite materials. Int. J. Plast. 26, 549-569.

Tekoglu, C., Leblond, J.B., Pardoen, T., 2012. A criterion for the onset of void coalescence under combined tension and shear. J. Mech. Phys. Solids 60, 13631381.

Tjahjanto, D.D., Turteltaub, S., Suiker, A.S.J., 2008. Crystallographically based model for transformation-induced plasticity in multiphase carbon steels Continuum Mech. Thermodyn. 19, 399-422.

Yang, Y., Wang, L., Zambaldi, C., Eisenlohr, P., Barabash, R., Liu, W., Stoudt, M.R., Crimp, M.A., Bieler, T.R., 2011. Characterization and modeling of heterogeneous deformation in commercial purity titanium. JOM 63, 66-73.

Zambaldi, C., Yang, Y., Bieler, T.R., Raabe, D., 2012. Orientation informed nanoindentation of alpha-titanium: indentation pileup in hexagonal metals deforming by prismatic slip. J. Mater. Res. (JMR): Focus Issue Instrumented Indentation 27 (1), 356-367. 